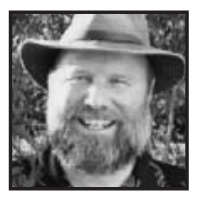

\title{
A Quest for a Theory and Practice of Authentic Assessment: An Arts-Based Approach
}

\author{
Joe Norris, St. Francis Xavier University
}

\begin{abstract}
Multiple intelligences and learning style theories articulate that there is a diverse population of students who learn and understand in a variety of ways. If assessment is meant to be authentic and just, teachers and school systems must expand their forms of assessment not only to accommodate, but also to encourage and celebrate multiple ways of knowing. This paper provides concrete examples of how arts-based assignments can be an authentic and rigorous form of assessment.
\end{abstract}

Darling-Hammond, Ancess, and Falk (1995) lament that:

With all of the burgeoning interest in alternative forms of assessment, there is yet very little rich description of how schools develop and use strategies such as portfolios, projects, performance tasks, and other documentation of student accomplishments to inform instruction and to stimulate learning. (p. xi)

$\mathrm{n}$ their book Darling-Hammond, Ancess, and Falk (1995) provide examples of projects, collaborative learning, anecdotal comments from student observations, and a primary language record. They recommend forms of self, peer, and supervisory assessment using contextualized learning, meta-cognition, and learning style theories to underpin their search for instruction that is meaningful, and assessment that is authentic. Early in my career as a teacher educator, I undertook a 
similar challenge seeking to create multiple ways of assessing student learning, framing my search with the question "How do I model multiple ways of knowing, doing, being, and learning in my teaching with pre-service and in-service teachers so that they may have exemplars to bring to classrooms of their own?" The question is an unbounded one (Henderson, 1992), not meant to lead to a resolution but, rather, to underpin practice. It has guided both my instruction and assessment over the past nineteen years as a teacher educator.

The paper describes a few ways in which I have attempted to incorporate the arts in my classroom, documenting some of the "rich description" that DarlingHammond, Ancess, and Falk request. Firstly, I link an arts-based approach to epistemological and educational theories, providing a rationale for multimedia forms of instruction and assessment that extend beyond the hegemony of word and number. Secondly, I provide examples of arts-based instruction that I have used to assist students in recognizing the artistry within. One must not only assign, but also teach, in ways that enable students to successfully undertake assignments. Thirdly, I provide examples of student work and their metacognitive logs as evidence, not only of their learning, but also of the power of arts-based assessment. I conclude by making explicit the value of arts-based assessment in education.

\section{From Theory to Practice}

Gadamer (1975) claims that whenever we translate something into another language, we recognize the incompleteness of both languages. Both contain traces not present in the other. For the translator, knowing, understanding, and meaning exist in the space between languages. In this space new meanings are found about both the concept and the language. In the act of translation, knowing becomes recursive.

As a drama teacher educator, I initially applied Gadamer's theory to lessons on choral speech. I found that the written text was too quickly translated into the spoken word resulting in the use of clichés. Without knowing what they were doing, I asked groups of students to colour the text of a poem and then instructed them to use the colour to guide their choices in how to divide the lines and to determine vocal inflections. Their conversations were rich and their decisions thoughtful as they used colour as a means of analysis. The act of translating into an intermediary medium enhanced student understanding, and corroborated Gadamer's theory. 


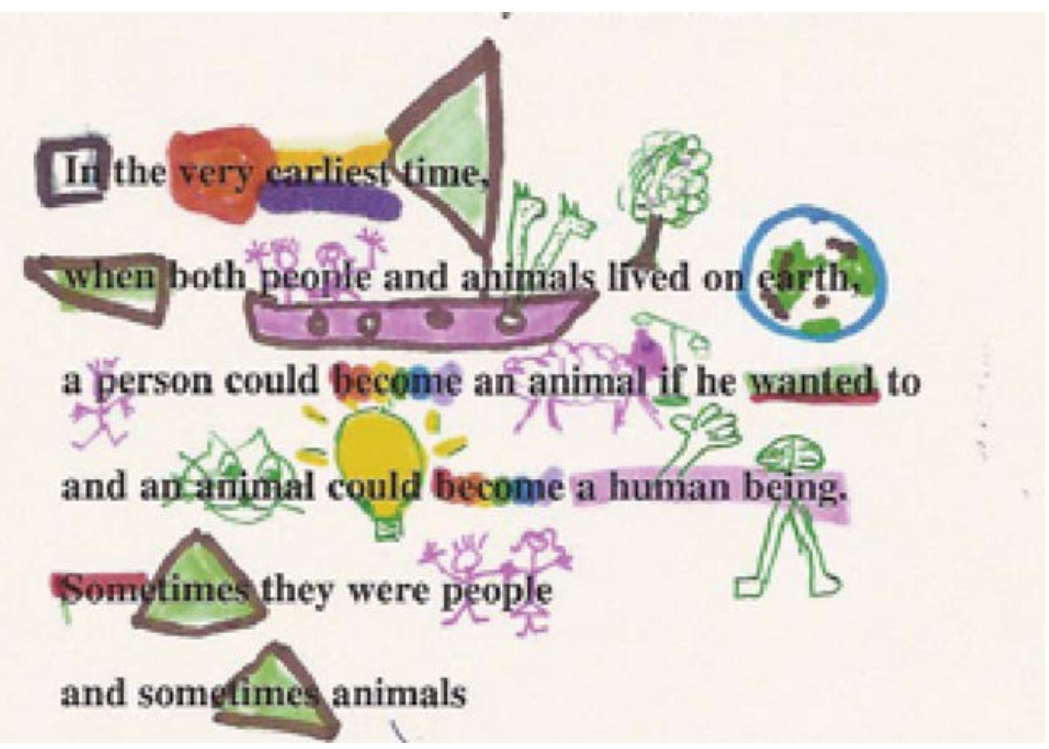

Fig. 1: Colouring of an Elizabeth Cleaver poem (Cleaver, 1995, p. ii)

MacLeod (1987) claims that that there are five ways of knowing and communicating the world, namely, through word, number, image, gesture, and sound. The use of the word symbol system is primarily taught in language arts; number in mathematics, science, and music; image in the visual arts; gesture in dance; and, sound in music. She concludes with the claim that drama integrates all five. As in the example shown in Figure 1, students translated words into colours and symbols and, then turned these colours and symbols into sounds (voice). The lesson also addressed a variety of multiple intelligences (Armstrong, 1994; Gardner, 1983). In this example, students utilized their linguistic, spatial, and interpersonal intelligences.

\section{Setting the Stage}

Over the years I have designed a number of multimedia lessons to engage students in the act of translation and processing course content by using a variety of intelligences.

Concrete poetry (Norris, 1995; Wihak \& Merali, 2007) has been used as an icebreaker. I begin many classes by asking students to draw their names on file cards 
turning the letters into shapes based upon their interests. I ask them to think about how they define themselves, thinking beyond the clichés. I use prompts such as, "What do you do? What interests you (hobbies, books, movies, collections, recreation)? What are you aspirations? What are your fears? Who are the important people in your lives? What puzzles you? What makes you happy, excited, angry, and sad? What are your teaching/research interests?"

I suggest that they spend some private time thinking about themselves before beginning the task. This reflection acts as a form of brainstorming and usually takes them away from the typical responses of self-introduction. I then provide an example with an explanation.

In Figure 2 a pipe forms my "J" referring to Magritte's painting, Ceci n'est pas une pipe (Magritte, 1928-29). I explain my attraction to postmodernism and the concept of representation. The green "o" is a labyrinth, a metaphor for one's life quest, introduced by Alex de Cosson (Irwin, Grauer, de Cosson, \& Wilson [2004]). The backwards "e" (a series of cul-de-sacs) represents my interest in

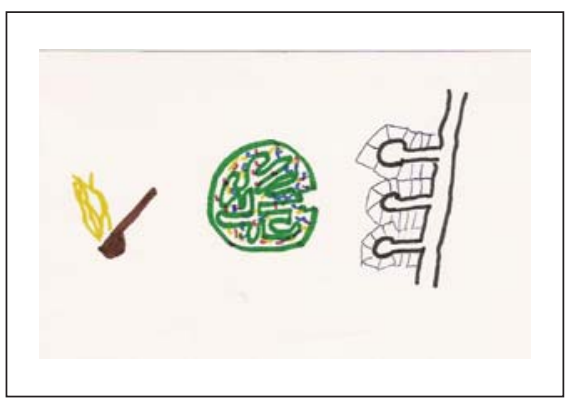

Fig. 2:"Joe" written in concrete poetry building new homes.

For approximately fifteen minutes students visit themselves through the art making. The self-introductions that follow are always 'sign'ificant as each person tells things about themselves they are willing to share.

Using the "mantle of the expert" (Wagner, 1976), I place students in soft roles as the experts. In a Principles of Learning class I enter as member of a search company hired to select an advertising agency (groups of students) to create a campaign for a new school founded upon holistic education principles. The students' readings on the topic are called their "briefing documents." Individually they are instructed to skim through the articles to find quotes that could promote the school on bus ads, newspaper spreads, billboards, and brochures. Once they find the quotes they are asked to choose the best ten as determined by the group. From that ten, one is to be chosen to create a mock-up of a poster. During this one to two-hour activity students are engaged in making their own meanings of the readings. 
The poster, as seen in Figure 3, takes its focus from the quote "transcend the here and now by constructing a new reality" (Barnes, 1976, p. 19). The small figure sitting on the frame is based upon what Paul Tillich considers the fatal pedagogical error, "to throw answers, like stones, at the heads of those who have

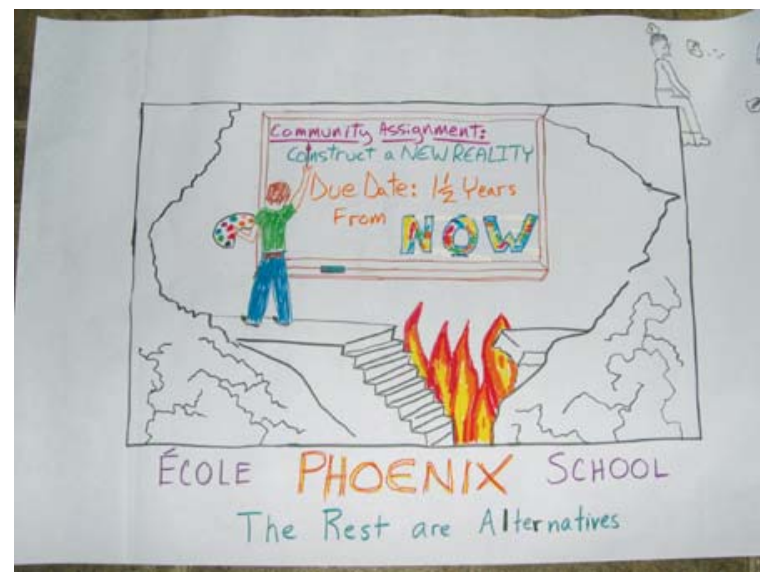

Fig. 3: Poster campaign advertising a holistic education school not yet asked the questions" (Brown, 1971, p. 15).

The activity demonstrates how students can translate course content visually, processing the information through multiple intelligences. On a few occasions I have used word-to-word translations where a list of quotes was turned into "found poetry" (Butler-Kisber, 2002) with a poster created from the poem.

Orff (1977) instruments, as shown in Figure 4, have been used to demonstrate musical intelligence as students explore emotions through sounds.

In addition to experiences like these that prepare students for an arts-based assignment, two other instructions are given.

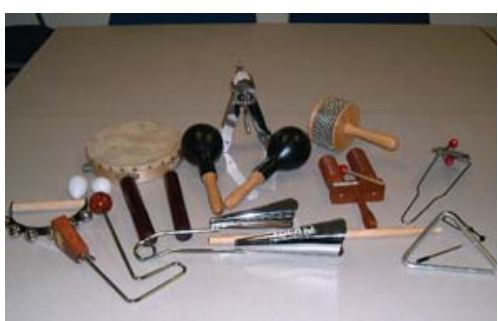

Fig.4: Samples of Orff instruments Firstly, students are asked not to predetermine their meanings but to allow the artwork to generate new meanings. I encourage them to enter what Neilsen (2002) calls the "liminal space": "Knowledge, like fiction itself, is liminal space. It never arrives. It is always on the brink. It is always a waiting space, a green room ..." (p. 208). It allows the media to construct meaning. Secondly, the students are asked to keep a metacognitive log, another tool of translation, in which they record their thoughts, decisions, and insights emerging from the process. Metacognition assists learners to become aware of their thinking (Carrell, 1989; Peters, 2000; Smith, Rook, \& Smith, 2007). This activity makes explicit the insights found as students document how word informs the art and the art informs the word in a recursive fashion. 
In keeping with Pinar's (1975) belief that "before we can learn to teach in such a way, we must learn to learn in such a way" (p.412), I take the time to let my students experience first hand arts-based processing prior to trying it on their own. Later, many return with exciting stories about how they incorporated the activities into their own teaching.

\section{The Assignments}

The following are examples of the artwork generated by the students and the metacognitive logs that accompanied them. They are empirical evidence of the depth of thought and degree of student engagement that can take place when one uses the arts to create personal meanings. Some of the artwork and the metacognitive logs were given to me as gifts at the end of the courses. Students gave me permission to use them in my future teaching assignments and in research. A few commented that they were grateful to have been able to view the works of previous students to inspire them and were happy to reciprocate for students of the future. All students whose assignments are cited were contacted by e-mail and sent the section that discussed their projects. They reconfirmed their willingness to share their works. The following is a small sample of my collection:

\section{Collage}

Collage has made up the bulk of the arts-based assignments. It seems to be a comfortable form for those who claim that they are not artists. For some, it was a new medium; for others, it was a welcome return. For me, it was a slow shift. I had never made a collage until a graduate student asked to do one as an assignment. To understand the process, I made one as a response to hers. The experience was powerful and I made notes about the process so that I could pass them on to others (Norris, Berry, \& Guercio, 1999). In subsequent classes I provide what I had experienced to my students to assist them in beginning one of their own.

Firstly, I searched magazines for pictures and phrases about the topic, avoiding constructing a preliminary collage in my mind. My general rule was, "Reject nothing that creates a reaction and edit later. One does not know where the subconscious may lead." Secondly, I delayed cutting and selected full pages. I wanted to reserve how I cut the piece for the context in which it would be placed. For example, as illustrated in Figure 5, with one picture of a path through a row of trees, I cut the 
path into triangles and pasted the pieces slightly apart in order to accentuate the sense of journey. For me, cutting was an act of interpretation.

Thirdly, the arranging and cutting evolved in a spiral fashion as each informed the other. In a photography magazine I found a series of lenses. I wanted to point them at the posed people. Rather than having a traditional rec-

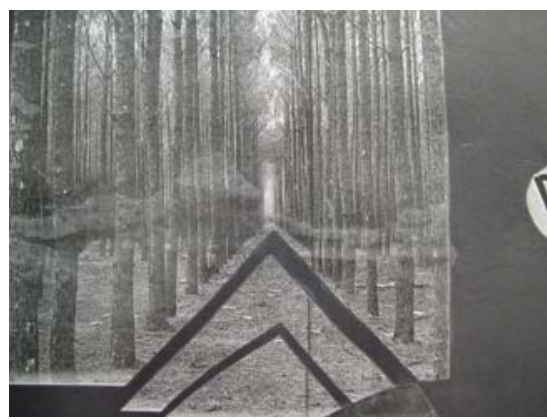

Fig. 5: Section of a collage response to a student collage tangular photograph of the lenses, I cut them, outlining their shapes. The placement of the lenses informed my cutting and vice versa.

Finally, even in the pasting, changes occurred. As one stroke of the paintbrush informed the next, I was open to a rearrangement, knowing that gluing meant no going back. This was a scary stage that required a leap of faith.

The collage provided a different avenue of reflective thought. It assisted me in understanding how others may visually process material and, like McDermott (2002), I learned how to utilize it as a meaningful course assignment.

\section{The Collage Work of Kathy F.}

Kathy was enrolled in my curriculum theory course in the summer of 2006.

For the first assignment, students could choose an educational theorist or theory to study and for the second, they could analyze a movie using curriculum theory concepts, undertake an arts-based approach, or, choose a second theory or theorist to examine. Kathy chose the collage as a means of thinking about gender stereotypes (see Figure 6). She entered the experience with preset assumptions: "Prior to the collage process I

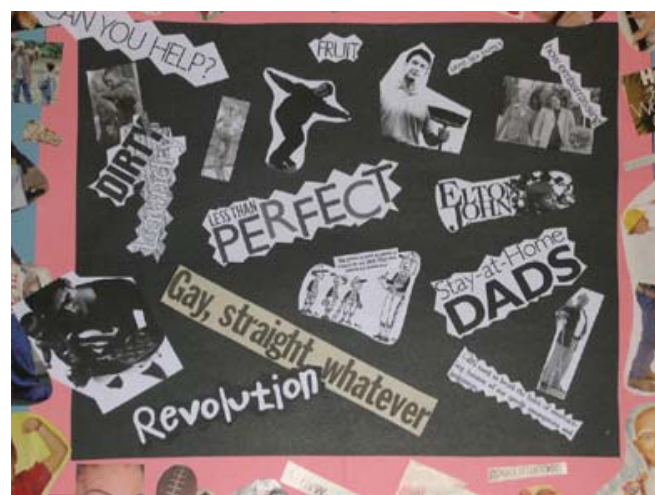

Fig.6: Collage entitled Gender Stereotype by Kathy F. 
truly felt that gender stereotypes were no longer an issue.... I wanted the collage to demonstrate the strides that our society has made..."

From her collection of images Kathy became aware that her perspective required revision: "This vision quickly changed as I was faced with blatant images of genderspecific professions..."

For those new to the collage experience, there is some doubt regarding the wealth of material that can be found. Usually, term papers are linear and logical, working from a stance of explanation. A paper acts as a form of transmission, demonstrating what one knows. Collage works at a metaphorical level and meanings are transformed as new connections are made with the found material and the thoughts generated through the topic chosen. Kathy was surprised that she easily found so much: "It was not at all challenging to find both pictures and words that fit the perceived female and male stereotypes.... I was not expecting to be overwhelmed by the amount of gender stereotypical material I found."

The curriculum theory class discussed how power and privilege are taught and reinforced within and outside of the school system. Kathy brought this understanding into the process: "Regardless of the age of the subjects, both male and female, the majority of the advertising images depicted them in their respective stereotypical roles."

From the meanings generated through the process Kathy turned her attention to the collage composition. Her arrangement and additions to the pictures and phrases, as articulated in her metacognitive log, demonstrated her depth of analysis:

... it became obvious to me that society's gender stereotypical beliefs completely surround and overshadow those individuals who may not fit into the prescribed belief system.

The border... will help to further illustrate for the audience how stereotypical we are as a society.

Meanings and forms co-emerge from the process as the medium informs the message (McLuhan, 1977) and vice versa. Scissors not only define shape but also define meaning:"I chose to cut the words in such a way that show very sharp edges; indicative of the belief that words can hurt..." 
The act of cutting/framing assists in the concept exploration/analysis clearly demonstrating the message within the medium. Arts-based assignments provide a variety of forms not available in the printed text alone.

Throughout the process Kathy incorporated terms and concepts she had encountered in the course. She used these to guide the process. The metacognitive log made her decisions explicit. Her understandings of the course were assembled in and through the collage. The collage did not merely act as a receptacle upon which meanings were placed but a process through which insights were generated.

Kathy concluded her analysis with a decision about placement. Here she extended her thesis through an actual disruption of the frame, creating a border-crosser (Giroux, 1992). She ended this section of her log with hope.

I have placed one image and one phrase in such a way that they overlap the border and the inside area of the collage.... to illustrate that there are individuals who may prescribe to components of both sides of the gender stereotype...

\section{The Collage Work of Shawn L.}

Shawn was enrolled in the same course as Kathy. She noted that changes in her focus occurred as the process progressed.

I wanted to head in the direction of "fair not always being equal." As I looked through the pages I saw lots of pictures that portrayed happy children in safe environments with their families.... This made me think of the different experiences, or lack of experiences that children have upon entering and during their schooling (see Figure 7).

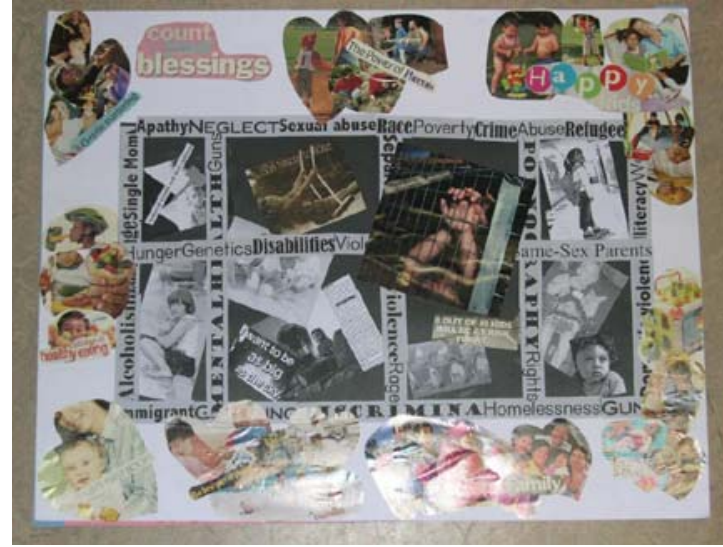

Fig. 7: Collage entitled Disparity in Education by Shawn L. 
Being open to the artistic process is an active surrender of the will (Nachmanovitch, 1990; Rutledge, 2004). Like the theatre adage, "the best acting is reacting," Shawn's metacognitive log reported that she allowed the pictures to guide her thinking. While she entered the process with a particular idea, it changed as a result of the materials at hand. In a similar vein, Ballesteros (2008) describes the inner state required to undertake Ikebana, the art of Japanese flower arrangement:

The learning does not come from merely memorizing the basics but from the process where students begin to attune to their inner selves, to the flowers and branches they are touching, to the surroundings that envelope them, and by extension to the world they exists in. Allow yourself to find beauty in harmony, beauty that only an uncluttered mind can grasp...

Shawn was able to abandon her original theme as the material "spoke" to her. Unlike one method of writing that suggests that one begins with a thesis and finds evidence to support it, an external hermeneutic (Werner \& Rothe, 1979), Shawn allowed the found material to redirect her thinking (internal hermeneutic). The metacognitive log served as a record of her emergent meaning-making.

Shawn's authorship lay in her responses to the things in front of her. They influenced her thinking as she both transformed the work and herself. The pictures transformed her, authoring her. "Authorship," "authority," and "authenticity" have the same root "auth" meaning "bringing about" (Klein, 1966). In the case of (auth)entic assignments the known cannot be separated from the knower as there is a dialectic relationship between the collage and the collagist. In a phenomenological sense the collage authors the collagist. The assignment is authentic in that it invites and encourages the authorship of the student rather than demanding a reproduction according to some predetermined outcome. The pictures influenced Shawn's thoughts as she used the course content to conceptualize them.

Shawn also used the collage as a springboard to reflect on her previous practice...

As I sit and look at this work of art I cannot help but think of a boy I taught many years ago.... I felt he was "lazy" and he spent quite a bit of time with me at recess completing unfinished class work and homework. Surprisingly, Jon seemed to enjoy spending time with me... 
I will never forget the day after he left, a little girl came to me and said that Jon had been crying on the bus ride home.... She went on to tell me that his mom would have parties late into the night and Jon was so scared that he would leave the house and hide in the woods. And I was worried about homework!

Students were encouraged to make the assignment an opportunity for renewal. Shawn's story is a courageous one. She turned her insights towards herself, reexamining her past with a new lens. Shawn's collage and metacognitive log demonstrated how she was able, through the collage, to utilize the course material to reexamine her own practices.

\section{Stained Glass}

Sue M. was enrolled in a graduate course called Principles of Learning that took an educational psychology perspective. I began with a curriculum theory focus using the concepts of the null and hidden curricula (Flinders, Noddings, \& Thornton, 1986) to demonstrate how educational psychology has underpinning epistemological assumptions.

Continental philosophers, even when they explicitly contest many assumptions underlying hermeneutics, have continued to produce detailed discussions that show how knowledge depends upon being in a world that is inseparable from our bodies, our language, and our social history — in short, from our embodiment (Varela, Thompson \& Rosch, 1992, p. 149).

Sue chose to make a stained glass window, illustrated in Figure 8, as a way to analyze Eisner's (1985) "five curriculum orientations" and immediately began to experience the interplay of form and content.

As I thought about each of these orientations, I was able to picture them in a very basic shape....As I let the light shine through the glass, I think of the possibilities that I as a teacher am able to shape the curriculum that is presented to me.

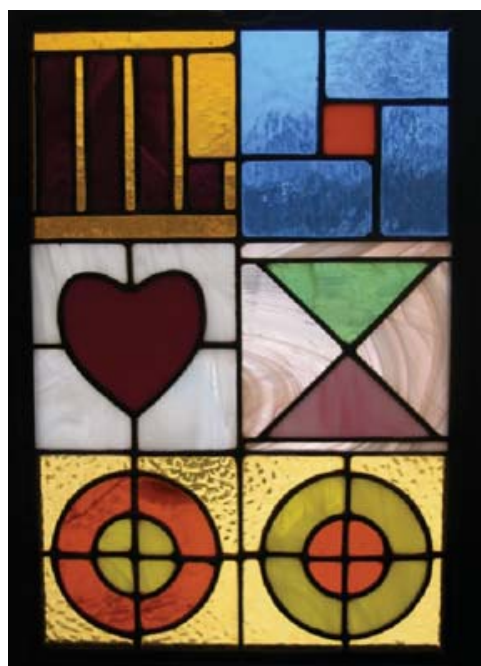

Fig 8: Stained glass work entitled Eisner's Five Curriculum Orientations by Sue M. 
The textures of the pieces of glass and her shaping them into form provided her with further insights into her life as a teacher. As she handed me the assignment she claimed that she was able to explore the concept much deeper than she would have if she had chosen a written paper. Through the act of translation, Sue escaped the hegemony of word as the new media "shed a different light" onto the topic.

Cognitive Processes.... I see this as the process being more important than the product.... The large purple rectangles represent the process; the small purple rectangle represents the product. In my class right now I would say that this orientation is present... (See Figure 9).

Sue continued that, in the future, she will focus her upcoming unit of dinosaurs to generate student thought and voice. Her lessons will not

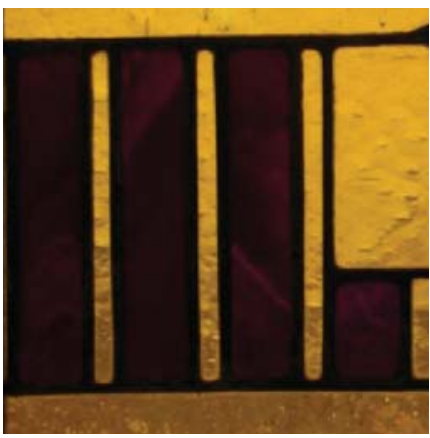

Fig. 9: Stained glass panel on Eisner's cognitive processes orientation merely focus on the content but on how her students think within the content. She demonstrated her use of theory to guide her practice. She also used theory to critique hegemonic practices in education...

...the goal of Academic Rationalism is to teach every student the, "best of the best." No time is to be wasted on subjects that are not "most worthy of study".... I have attempted to show this in glass by having a small orange square inside a large blue square. This shows that we get the best of some things, but it is not everything (see Figure 10).

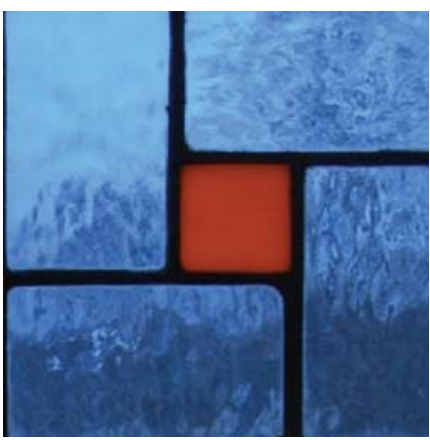

Fig.10: Stained glass panel on Eisner's academic rationalism orientation

Visually, Sue conceptualized the null curriculum (what is not taught) revealing its limitations. She also reflected upon her previous teaching and extended it into the future with a challenge to the Self. She found/created personal relevance through the project.

In Personal Relevance children take responsibility of their own learning by investigating things that they feel are important to them.... I know that in my own classroom, I would like to have the children more involved in their 
own learning and be given the opportunity to have more input into their curriculum.... The heart represents personal relevance... (See Figure 11).

Sue recognized that student engagement comes from a place where spaces are created for student voice (Zyngier, 2007).

Through the assignment Sue used visual metaphors to add to her understanding of the course content and brought this understanding to assess her role in the present educational environment. Again, she made this a challenge in her practice.

The next panel represents curriculum as technology. In this curriculum, meansends are all important.... I see this as a balancing act.... The triangles are point to point. One triangle represents the means while the other, the ends. Since the tips are touching, one wrong move and the top triangle will fall.... I am going to make a conscientious effort to include the other curriculum styles into my program of studies (See Figure 12).

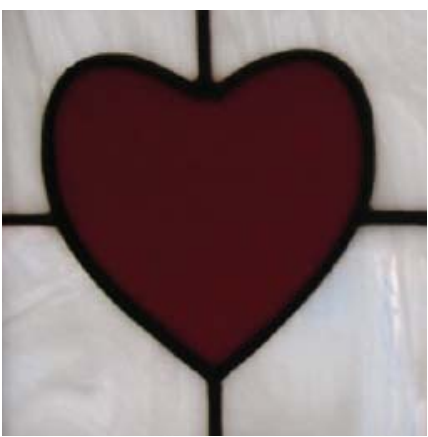

Fig.11: Stained glass panel on Eisner's personal relevance orientation

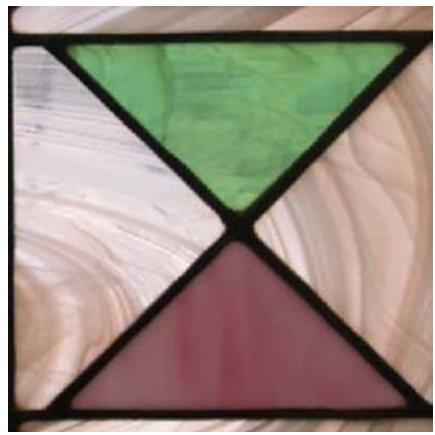

Fig. 12: Stained glass panel on Eisner's curriculum as technology orientation

For the final orientation Sue created two panels, as illustrated in Figure 13, exploring the relationship between the two players, the individual and society.

With the final orientation I see as two different styles. Although both deal with society, I see "social adaptation" as society telling us what the problem is and what we must do to correct it.... "Social reconstruction" on the other hand is each individual seeing a problem in society that he/she chooses to work toward to solution.... I showed social adaptation as the individual being the small yellow circle in the middle with society being the dark brown circle surrounding it... Social reconstruction is represented 
by the little brown circle (society) surrounded by the large yellow circle.

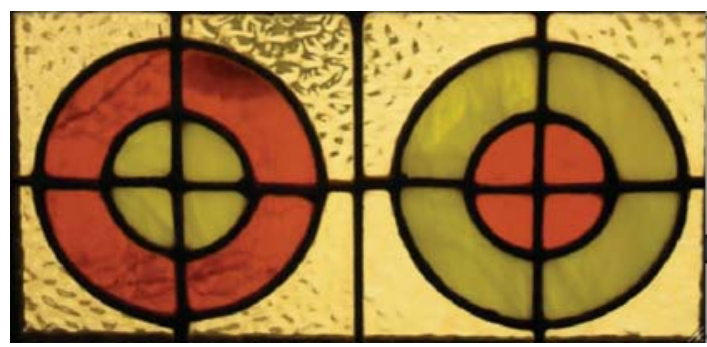

Figure 13: Stained glass panel entitled On Democracy in Education by Sue L.

\section{Floor Cloth}

Sue L. took the course Principles of Learning in the same year as Sue M. She had previously studied the making of floor cloths and chose this as her medium or threshold to new understandings.

I decided to work with my knowledge and new awareness of my desire for a more democratic space for learning, through the creation of a floor cloth about democracy. I thought it might serve for me as a portable reminder, and as a meeting place for open discourse and conversation.

Sue's log pointed out that the understanding of democratic teaching is ephemeral. Her desire for future conversations and her goal to implement it indicated her belief in the fluidity of knowledge, that meanings are "placeholders" (Osberg, Biest, \& Cilliers, 2008) until new insights emerge. The mat and her thoughts were potential energy waiting for fruition though conversations with others (Barber, 1989).

I wanted to represent the spherical central essence of the orchid as transparent and illusory, and to represent the illusory transparent depth of the democratic ideal to which attainability though transparent, is also illusive in nature: a rare thing of beauty like an orchid or a learner whose basic needs are nurtured toward self-efficacy and beyond (See Figure 14).

Sue's project fluctuated between plan and inspiration as she collected her materials and readings with potential ideas waiting for the right moment to act. Harman and Rheingold (1984) describe the creative act as information, perspiration, incubation, and illumination. Information is the gathering stage in which Sue collected her materials. Perspiration is the working stage and Sue, in her previous paper and work with other floor cloths, had amassed the cognitive and artistic skills necessary for the task. 
She recognized that waiting for incubation was an important stage.

The notion of democracy and its exploration seemed to be, not of the obvious black and white surface, but amongst shades of gray. That choices and occasions of gray area not often given time, perhaps ignored, or part of hidden agendas, or partially nullified.... I thought

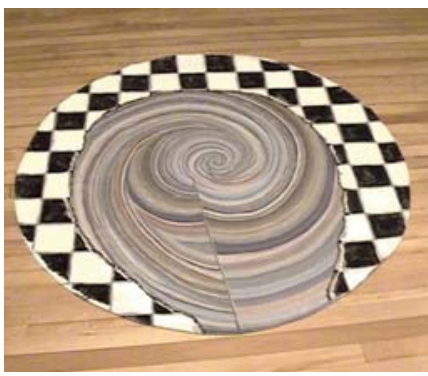

Fig. 14: Floor mat on democratic education surrounded by a structured school system that exploring these gray images, (made by adding black) and seeking clarification might lead me to further understanding of the ideal of democracy. I waited... (again see Figure 14).

Along this vein Poincaré tells a story of the importance of "time-out":

Disgusted with my failure, I went to spend a few days at the seaside, and thought of something else. One morning, walking on the bluff, the idea came to me, with...the characteristics of brevity, suddenness and immediate certainty. (Poincaré, 1970, p. 82)

He continues with the claim that "Often when one works hard at a question, nothing good is accomplished at the first attack. Then one takes a rest, longer or shorter, and sits down anew to the work" (Poincaré, 1970, p. 83). Time away, rest, incubation, for some seems to be a part of the creative act.

McGuinness (2007) claims that waiting before the work is procrastination while waiting after the work is incubation. I encourage my students to "wait" and am prepared to extend the 'dead'lines that often rush a project to completion. Sue reported that waiting for the paint to dry was an incubation time and that doodling assisted her in finding/creating her metaphor.

Since I had been doodling and sketching a checkerboard pattern throughout my first paper.... I decided to sketch and measure using divine rectangles from a center point, creating nautilus shape. I stopped when I came to the outer edge of the circle. I knew that the black and white checkerboard edge had to form the outer part of the circular shape... 
For me, meandering is part of the creative process.

Throughout her log Sue made explicit her thoughts on the topic and her artistic choices. The recursive translation of one to the other created a dialogue between form and content, enhancing both as they co-inspired with each other. Through the metacognitive Sue did not represent how she understood the course material but told a story of how meanings and the artwork co-emerged through the process.

\section{Music}

$\mathrm{Al}$, a musician, took a curriculum theory course in 2000. I have always encouraged musical assignments and have publicly pondered what different theoretical classrooms would sound like. To date, Al has been the only student to take up this challenge. With his jazz band, he explored Aoki's (2005) three curriculum orientations by producing a CD (See Figure 15)...

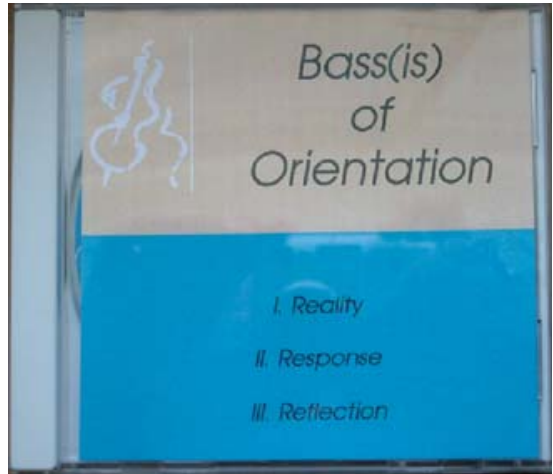

Fig. 15: Bass(is) of Orientation by AI C.

Upon first reading Curriculum in a New Key by Ted Aoki, I was left confused about how the three orientations he discusses could be used in a classroom and how they related to each other. I was determined to understand what I had read, so I searched for ways to do so. My quest led me back to my roots in the field of music. I started to equate the reference in the title of "a new key" to that of modulation in a music piece.

When I taught at the University of Alberta I had at my disposal a "drama education studio" that was originally designed as a television studio. Al and his ensemble performed for the class and recorded a jazz piece for each orientation. 
Al describes Movement \#1 with these words:

Knowledge about the world is gained through guided observation and carefully designed and controlled manipulation. Composed in a standard 32-bar harmonic structure, this movement exemplifies ALL THAT IS TRADITIONAL

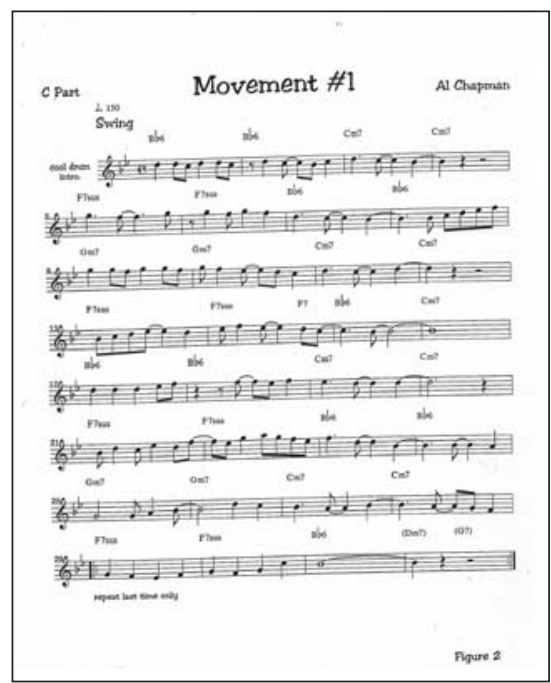

Fig.16: Bass(is) of Orientation: Reality Movement \#1 (Empirical Analytic) (Click on Musical Score for Sound)

\section{Bass(is) of Orientations: Response - Movement \#2 (Situational Interpretive) IMPROVISION ON A PAINTING OF A DOOR NO WRITTEN MUSIC: (Click on This Sentence for Sound)}

Al describes Movement \#2 in this fashion:

In a social situation wherein things, people, and events move together, there are many ways in which they are given meaning by the people in the situation. In the situational interpretive domain, essence and/or meaning are discovered through conversation. The lack of any formal melodic or chordal structure in this movement allows the individual musicians to partake in a musical dialogue that will create an experience that is "emergent in nature."

The view through the open door is different for each individual. What we see is based upon where we have been and where we are going. In the situational interpretive domain, essence and/or meaning is discovered through conversation or dialogue. The art of improvising is to communicate to others through a medium other than dialogue. 
Al's summation of Movement \#3 is the following:

Reflection by the participants allows new questions to emerge which, in turn, leads to more reflection. Embedded in this movement is a brief change in melodic style that represents a changing perspective that can be brought about by the act of reflection.

After the performance the class discussed what they had heard in the music, relating it to the article. It yielded many insights as we articulated where

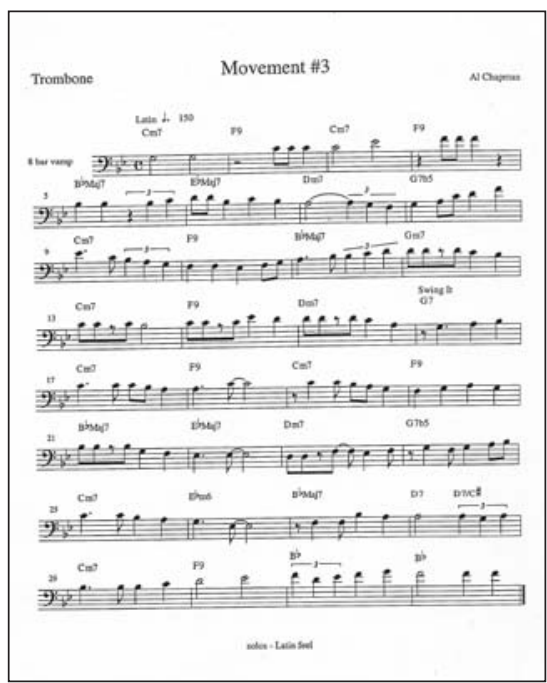

Fig. 17: Bass(is) of Orientation: Reflection Movement \#3 (Critically Reflective) (Click on Musical Score for Sound) the music took us. My major insight occurred much later while replaying the music for other classes. I had often said that while I identified with critical theory and its examination of power and privilege, I would not invite critical theorists to supper because you cannot relax around them. Over the years my experiences at conferences have taught me that critical theorists can be as didactic as those with a traditional orientation. While listening to the music two aspects became clear: firstly, the first and third movements sounded more alike than the second movement, which was my preferred piece. I tended to be drawn to emergent ephemeral things in life rather than those highly structured Secondly, in the third movement there was an echo. The music followed a rhythm and then a horn blasted with what I call "dat-dat-dat." In describing what I heard, I rephrased it to 'but, but, but'. With critical theory, there can be a constant looking for political fault with negative comments about what is being presented. For me this resembled a spanking. This was something that was embedded in my subconscious level and only through listening to the music could I bring it to words. The act of translation made this explicit. The situational interpretive approach creates space for all participants' voices, making it emancipatory in nature, perhaps even more so than the critical reflective orientation.

For Al, the process was the focal point of the course. While he gleaned greater understanding about the reading he also found a way back to his art. 
This journey was one of great personal discovery. Over the last few years the role of teacher left little time for the art of composition or musical development... I was determined to create a path that would allow me to reacquaint myself with my voice through music.

The opportunity to compose and perform this piece helped to begin to answer those questions for me.... On Tuesday, April $11^{\text {th }}$ the boundaries in which I had been enclosed.... vanished.

Such is my hope for all students. Besides articulating his understanding of the Aoki reading in music and word, Al attested that his creativity was fostered.

\section{Discussion}

\section{Creativity}

My doctoral research question was, "What do we do as teachers that foster creativity and what do we do to inhibit it?" (Norris, 1989). My career has been spent designing creative spaces for my students so that they would bring such activities to their teaching. A large number of them reported that they have done so. In the courses that I teach and in the assignments that I design my aim is to be more fostering than inhibiting, reversing the trend of rote learning that can stifle the creative spirit (Robinson, 2006). With a variety of choices, employing multiple ways of knowing, students can engage with the course content in a number of ways, using a variety of forms. Through the metacognitive logs students demonstrate that their works are not mere representations but co-emergences between themselves and the world.

If, however, our lived world does not have predetermined boundaries, then it seems unrealistic to expect to capture commonsense understanding in the form of a representation - where representation is understood in its strongest sense as a re-presentation of a pregiven world. Indeed, if we wish to recover common sense, then we must invert the representationist attitude by treating context-dependent know-how not as residual artifact that can be progressively eliminated by discovery of more sophisticated rules but as, the very essence of creative cognition. (Varela, Thompson \& Rosch, 1992, p. 148) 
Through the act of art making the students recreated meanings, transforming what they knew into revised conceptual placeholders that may go through more revisions based upon future experiences. The projects created occasions for learning that the students enacted (Kieren, 1995). The log recorded their learning and could be assessed as both a process and a product.

\section{Rigour}

Many students have verbally claimed that the assignment took a lot of time, was hard work, extremely insightful, enjoyable, and spiritual as they spent peaceful time connecting with themselves and the course content through the art making. The medium chosen acted as a threshold allowing the student to focus deeply as the message and the medium co-emerged. One student said that she had spent the Monday of the long weekend in May lost/absorbed in the process as she returned to her charcoal. It was a returning to a type of experience that she had long forgottenone that she wanted more of for herself and her students.

In tandem the art work and the metacognitive log demonstrated the amount of work and the depth of thought that the students have processed.Through refection they exhibited what the course content meant to them and the connections that they had made. With a deep connection to the process they seemed to have been more intrinsically motivated, committing self to the journey. As an emergent process, the assignment took on a life of its own, stimulating metaphorical thought (Gordon, 1961), creating new possibilities. The work could not be completed until it said so, creating its own internal rigour.

\section{Authenticity}

For me, authentic learning and assessment experiences integrate the knower and the known. The role of the teacher is to provide both content and processes that create spaces or thresholds through which students can take control of their own learning. The content, acting as a muse, evokes thoughts that guide artistic choices. The content, however, is not fixed but changes as the students rework it. In constructivist (Schunk, 1991) classrooms students are brought to the subject through teacher-designed scaffolding. In enactivist (Kieren, 1995) classrooms students become both consumers and producers of knowledge (Freire, 1994) as they transform understanding in unpredictable ways making it immune to the convergent constraints of standardized testing. The art-making media play a major role in meaning construction as the medium influences thoughts on the choices made, making explicit the interconnectedness of the medium and the message (McLuhan, 
1977). Collectively, course content, media, and the learner, bring previous knowledge, skills, and creativity to the work as students translate the course material into new forms. Authentic assessment, like authentic learning, must have the students as one of its authors.

\section{References}

Aoki, T. (2005). Toward curriculum inquiry in a new key. In W. Pinar \& R. Irwin (Eds.), Curriculum in a new key (pp. 89-110). Mahwah, NJ: Lawrence Erlbaum Associates.

Armstrong, T. (1994). Multiple Intelligences in the classroom. Alexandria, VA: Association for Supervision and Curriculum Development.

Ballesteros, M. (2008). Sogetsu Ikebana lesson details. Retrieved May 10, 2008, from http://www.mirochi.com/mirochi/Lesson Details.html

Barber, M. (1989). Alma Gonsalvez: Otherness as attending to the Other. In A. B. Dallery \& C. E. Scott (Eds.), The question of the Other (pp. 119-126). New York: State University of New York Press.

Barnes, D. (1976). From communication to curriculum. Markham, ON: Penguin Books.

Brown, G. I. (1971). Human teaching for human learning. Markham, ON: Penguin Books.

Butler-Kisber, L. (2002). Artful portrayals in qualitative inquiry: The road to found poetry and beyond. Alberta Journal of Educational Research, 48(3), 229-239.

Carrell, P. L. (1989). Metacognitive awareness and second language reading. The Modern Language Journal, 73(2), 121-134.

Cleaver, E. (1985). The enchanted caribou. Toronto, ON: Oxford University Press.

Darling-Hammond, L., Ancess, J., \& Falk, B. (1995). Authentic assessment in action. New York: Teachers College, Columbia University.

Eisner, E. (1985). Five basic orientations to the curriculum. In E. Eisner (Ed.), The educational imagination (pp. 61-86). New York: MacMillan.

Flinders, D. J., Noddings, N., \& Thornton, S. J. (1986). The null curriculum: Its theoretical basis and practical implications. Curriculum Inquiry, 16(1), 33-42.

Freire, P. (1994). Pedagogy of hope: Reliving pedagogy of the oppressed. New York: Continuum.

Gadamer, H. (1975). Truth and method. New York: Crossroad.

Gardner, H. (1983). Frames of mind: The theory of multiple intelligences. New York: Basic Books.

Giroux, H. (1992). Border crossings: Cultural workers and the politics of education. New York: Routledge, Chapman and Hall,

Gordon, W. J. J. (1961). Synectics. New York: Harper \& Row.

Harman, W., \& Rheingold, H. (1984). Higher creativity. Los Angeles, CA: Jeremy P. Tarcher.

Henderson, J. (1992). Reflective teaching: Becoming an inquiring educator. Toronto, ON: Maxwell MacMillan Canada.

Irwin, R. L., Grauer, K., de Cosson, A. \& Wilson, S. (2004). Grounded Inquiry through A/r/tography. Paper / Performance presented at the annual AERA Conference, Arts-based Educational Research SIG, San Diego, CA.

Kieren, T. (1995). Teaching mathematics (in the middle): An enactivist view of learning and teaching mathematics. Publication from the Center for Mathematics, Science, and Technology Education. Retrieved May 10, 2008, from www.ioncmaste.ca/home page/discussion_group.html 
Klein, E. (1966). A comprehensive etymological dictionary of the English language. New York: Elsevier.

MacLeod, J. (1987). The arts and education. Paper presented at the keynote address given at an invitational seminar co-sponsored by the Fine Arts Council of the Alberta Teachers' Association and The University of Alberta, Faculty of Education, Edmonton, $\mathrm{AB}$.

Magritte, R. (Artist). (1928-29). Ceci n'est pas une pipe [Painting].

McDermott, M. (2002). Collaging pre-service teacher identity. Teacher Education Quarterly, 29(4), 53-68.

McGuinness, M. (2007). What's the difference between incubation and procrastination? [Electronic Version]. Retrieved May 10, 2008, from http://www.wishfulthinking. co.uk/blog/2007/10/23/whats-the-differ ence-between-incubation-and-procrasti nation/

McLuhan, M. (1977). The medium is the massage. New York: Random House.

Nachmanovitch, S. (1990). Free play: The power of improvisation in life and the arts. Los Angeles, CA: Jeremy P.Tarcher.

Neilsen, L. (2002). Learning from the liminal: Fiction as knowledge. The Alberta Journal of Educational Research, XLVIII(3), 206-214.

Norris, J. (1989). Some authorities as co-authors in a collective creation production. Unpublished doctoral dissertation, University of Alberta, Edmonton.

Norris, J. (1995). The use of drama in teacher education: A call for embodied learning. In B. Warren (Ed.), Creating a theatre in your classroom (pp. 279-305). North York, ON: Captus Press.

Norris, J., Berry, G. \& Guercio, G. (1999). Collage creation as meaning making. Paper presented at the Advances in Qualitative Methods Conference. Edmonton, AB.

Orff, C. (1977). Music for children (Vol. 2). New York: Shott.

Osberg, D., Biest, G., \& Cilliers, P. (2008). From representation to emergence: Complexity's challenge to the epistemology of schooling. Educational Philosophy and Theory, 40(1), 213-227.
Peters, M. (2000). Does constructivist epistemology have a place in nurse education? Journal of Nursing Education, 39(4), 166-170.

Pinar, W. (1975). Curerre: Toward Reconceptualization. In W. Pinar (Ed.), Curriculum theorizing. Berkeley, CA: McCutchan.

Poincaré, H. (1970). Mathematical creation. In P. E. Vernon (Ed.), Creativity (pp. 77-88). New York: Penguin Books.

Robinson, K. (2006). Do schools kill creativity? Technology, Entertainment, Design (TED). Retrieved May 10, 2008, from http://www .ted.com/index.php/talks/view/id/66

Rutledge, M. (2004). Dance as research: The experience of surrender. Unpublished doctoral dissertation, University of Alberta, Edmonton.

Schunk, D. (1991).Constructivism. In D. Schunk (Ed.), Learning theories (pp. 285-328). Columbus: Merrill Prentice Hall.

Smith, K. S., Rook, J. E., \& Smith, T. W. (2007). Increasing student engagement using effective and metacognitive writing strategies in content areas. Preventing School Failure, 51(3), 43-48.

Varela, F., Thompson, E., \& Rosch, E. (1992). The embodied mind: Cognitive science and human experience. Cambridge, MA: MIT Press.

Wagner, B. J. (1976). Dorothy Heathcote: Drama as a learning medium. Washington, DC: National Education Association.

Werner, W., \& Rothe, P. (1979). Doing school ethnography. Edmonton, AB: Department of Secondary Education, University of Alberta.

Wihak, C., \& Merali, N. (2007). Racial/cultural identity: Transformation among schoolbased mental health professionals working in Nunavut. Canadian Journal of Education, 30(1), 291-322.

Zyngier, D. (2007). (Re)conceiving student engagement: What the students say they want. Putting young people at the centre of the conversation. LEARNing Landscapes, 1(1), 93-114. 


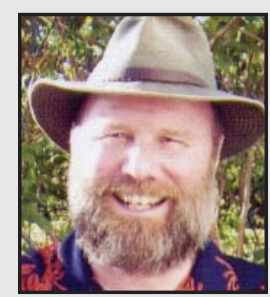

Joe Norris, a Professor of Education at St. Francis Xavier University, is an advocate of the arts as a way of knowing and integrates this belief in his teaching and research. He is committed to the fostering of student voice. His publication Learning to Teach Drama: A Case Narrative Approach, coauthored with Laura McCammon and Carol Miller, contains case narratives written by both student and cooperating teachers. As the former artistic director of Mirror Theatre, he has assisted casts in writing, performing, and conducting workshops for social issues theatre on bullying, prejudice, human sexuality, substance abuse, and education. His upcoming book, Playbuilding as Qualitative Research (in press), is based upon this work. His latest project, duoethnography, cocreated with Rick Sawyer, encourages texts written like play scripts, making the dialogue between the coauthors explicit. 